\title{
Effect of Conventional Abdominal Binder on Diastasis Recti Abdominis in Post-Partum Women
}

\author{
Sagarika Shashank Patwardhan ${ }^{1}$, Vrishali Baban Pawar ${ }^{2}$, Smita Chandrakant Patil ${ }^{3}$ \\ 1, 2 Department of Physiotherapy, Krishna Institute of Medical Sciences, (Deemed to \\ Be University), Karad, Maharashtra, India, ${ }^{3}$ Department of Musculoskeletal Sciences, \\ Krishna College of Physiotherapy, KIMSDU, Maharashtra, India,
}

\section{ABSTRACT}

\section{BACKGROUND}

Pregnancy creates a radical change in a woman's life. The physical, hormonal, and psychosocial changes during pregnancy affect the quality of life in post pregnancy phase. Diastasis recti abdominis (DRA) is one of the most common problems seen in post-partum period. DRA is a separation between two bellies of the rectus abdominis muscle connected by the linea alba. A significant DRA, if left untreated at the right time can lead to delirious complications. Prior researches have shown that diastasis recti abdominis is a very common condition seen in the post-partum period. Previous studies have shown that DRA can be reduced with help of an abdominal binder but have very less recorded data. Fewer studies have been conducted showing the combined effect of use of abdominal binder with core strengthening exercises in reduction of DRA. The purpose of this study was to find out the effect of a conventional abdominal binder on diastasis recti abdominis in post-partum women and determine the effect of a conventional abdominal binder on diastasis recti abdominis in post-partum women.

\section{METHODS}

This experimental study included 9 post-partum women with significant DRA. Their age ranged from 25 - 30 years, body mass index (BMI) less than $40 \mathrm{~kg} / \mathrm{m}^{2}$. The outcome measures included DRA, lumbar lordosis measurement, low back pain and disability in post-partum period. The subjects were instructed to use an abdominal binder and were taught core strengthening exercises up to 3 months post-partum.

\section{RESULTS}

The obtained results show that there is statistically significant reduction in DRA after use of conventional abdominal binder and exercises. The before treatment values for mean and standard deviation at, above and below umbilicus were $59.39 \pm$ $14.24,51.87 \pm 12.37,38.15 \pm 12.13$ respectively which reduced to $41.19 \pm 12.21$, $37.76 \pm 12.98,30.76 \pm 8.94$ respectively after using conventional binder with exercises for 3 months. The P value at all three levels of measurements namely - at, above and below umbilicus was $<0.0001$ which is statistically considered to be extremely significant. The study duration was of 3 months.

\section{CONCLUSIONS}

The findings conclude that the mean value of DRA decreases with the help of abdominal binder and core strengthening exercise regime. Hence, the abdominal binder and core strengthening exercises were effective in reducing the DRA.

\section{KEY WORDS}

Abdominal Binder, Diastasis Recti Abdominis, Rectus Abdominis, Core Strengthening, Post-Partum
Corresponding Author: Dr. Sagarika Shashank Patwardhan, Krishna College of Physiotherapy, KIMSDU, Karad,

Maharashtra, India.

E-mail:

sagarikapatwardhan123@gmail.com

DOI: $10.14260 /$ jemds/2021/461

How to Cite This Article:

Patwardhan SS, Pawar VB, Patil SC. Effect of conventional abdominal binder on diastasis recti abdominis in post-partum women. J Evolution Med Dent Sci 2021;10(30):2255-2259, DOI: $10.14260 / \mathrm{jemds} / 2021 / 461$

Submission 02-05-2021,

Peer Review 04-07-2021,

Acceptance 11-07-2021,

Published 26-07-2021.

Copyright (C) 2021 Sagarika Shashank Patwardhan et al. This is an open access article distributed under Creative Commons Attribution License [Attribution 4.0 International (CC BY 4.0)] 


\section{BACKGROUND}

The anterolateral abdominal wall consists of four paired major muscles, external and internal oblique (oblique fibers), transverse abdominis (horizontal fibers) and rectus abdominis (vertical fibers) which span from thoracic cage to pelvis and are connected to the spinal column by a corset like fascia i.e. thoraco lumbar fascia. ${ }^{1}$ The physical, hormonal and psychosocial changes affect the quality of life in post pregnancy phase. The relaxin hormone secreted during pregnancy induces overall laxity in joints, muscles and ligaments. The collective effect of relaxin hormone and stretching of abdominal musculature and linea alba to accommodate the growing fetus creates separation between two bellies of rectus muscle. ${ }^{2} \mathrm{~A}$ divarication can be a result of multiple number of pregnancies reducing tone of the abdominal muscles, carrying a large baby, having a higher body mass index, multiple birth pregnancies, excess amount of uterine fluid and if strenuous workload is applied on abdominal muscles during pregnancy.3,4,5 Diastasis recti abdominis is defined as separation of rectus abdominis muscle at the linea alba which connects the two parts of this muscle. ${ }^{6}$ A descriptive study states that DRA is seen during pregnancy - $27 \%$ in $2^{\text {nd }}$ trimester and $66 \%$ in $3^{\text {rd }}$ trimester. $36 \%$ of women between 5 week and 3 months post-partum had observed continuing of displacement of separation of diastasis recti, $30-70 \%$ of pregnant women are affected with DRA.7,8 It can persist for $30-60 \%$ women in puerperium up to 12 weeks at different sites along the linea alba. $52 \%$ of DRA cases occur at the umbilicus, $36 \%$ occur above the umbilicus, and $11 \%$ occur below the umbilicus. ${ }^{7}$ The occurrence of DRA ranges from mild to severe: Mild - 2.5 - 3.4 $\mathrm{cm}$ wide and $12 \mathrm{~cm}$ long, severe - greater than $5 \mathrm{~cm}$ and entire length of rectus muscle. $4,5,9-12$

The diastasis is a gap between the recti abdominal muscle greater than $25 \mathrm{~mm}$ or any separation larger than $2 \mathrm{~cm}$ by caliper method and 2 finger widths is considered significant.7,8,10,13 Current physiotherapy for treating DRA General TA muscle training was preferred by $89.2 \%$ of the physical therapists. $87 \%$ use pelvic floor training and $82.8 \%$ incorporate TA training into functional tasks. General abdominal training was selected by $34.8 \%$. If DRA persists after 12 weeks post-partum, it has delirious effects such as weakening of the core muscles and trunk instability, modifications in intra-abdominal pressure, alterations leading to a poor posture, lumbo-pelvic pain and abdominal hernia. It creates problems in future deliveries.

All these effects create a negative impact on patient's health. $56 \%$ instruct their patients with DRA to wear the abdominal binder with strenuous activities, $39.7 \%$ instruct patients to wear the abdominal binder while performing exercises, $38.5 \%$ recommend the binder for use during activities of daily living.

Abdominal binder provides support and compression by mimicking facial tension of transversus abdominis thus providing biofeedback to assist transversus abdominis activation. $^{3}$ So, this study was conducted to determine the effect of a conventional abdominal binder combined with core strengthening exercises in post-partum women.

\section{METHODS}

This study falls under pre-experimental research study design under the sub-group one group pre-test post-test research design. It was carried out among 9 post-partum women. The sample size was decided by the formula ${ }^{9}$

$\left[\mathrm{SD}\right.$ conventional ${ }^{2}+\mathrm{SD}$ modified $\left.^{2}\right] * 7.8 /[$ Mean conventional - Mean modified $]^{2}$

SD conventional $=0.02$

$\mathrm{SD}$ modified $=0.04$

Mean conventional $=0.56$

Mean modified $=0.6$

The participants were selected by random sampling method based on the inclusion and exclusion criteria. The subjects selected were Krishna Hospital "deemed to be" university - Gynaecology Ward. Ethical approval was obtained from Institutional Ethical committee - KIMSDU, Karad. The total study duration was of 3 months after obtaining the ethical clearance. The study commenced in January 2020 with monthly follow up readings up to March 2020.

\section{Inclusion Criteria}

Post-partum women between the age 20 - 35 years following a vaginal or lower segment caesarean section (LSCS) delivery with DRA greater than $2 \mathrm{~cm}$ or $25 \mathrm{~mm}$ and both primiparous and multiparous women who were willing to participate in the study were chosen.

\section{Exclusion Criteria}

Females with previous abdominal surgeries, previous history of low back pain prior to pregnancy, patients having respiratory issues, allergy to the material of the conventional binder, spontaneous abortion, still birth, premature delivery before 32 weeks of gestation were excluded from this study. The written informed consent was taken from the subjects and patients were briefed in detail about the study. The pre assessment was taken on $7^{\text {th }}$ day post-partum. The following three readings were taken monthly up to 3 month's postpartum. All participants were instructed not to participate in any other exercise programme during the study period.

Patients were assessed for the following outcome measures -

1. DRA that is the inter recti distance (IRD) was measurement by Mitutoyo dial up caliper. It can measure a distance between two recti up to $150 \mathrm{~mm}$ in increments of $0.01 \mathrm{~mm}$ with durable super polyamide metal and fibre glass construction. The patients were positioned in crook lying position as the therapist palpated the medial edge of the rectus abdominal muscle at three sites: $4.5 \mathrm{~cm}$ above umbilicus, at umbilicus and $4.5 \mathrm{~cm}$ below umbilicus. The measurement at all three sites was first taken by finger method followed by dial up caliper. Then therapist instructed the subject to raise her head and shoulders above the plinth, at this point distance between two recti was assessed in $\mathrm{mm}$. Three 
trails were taken for measuring and the mean was calculated for each measurement.

2. Lumbar Lordosis was measured using a flexible curve ruler. Patient was asked to stand erect and the area to be measured was exposed. The tip of the ruler was placed at the level of the $12^{\text {th }}$ thoracic vertebrae and as the ruler was flexible, it was adjusted according to the curve in lumbar region. The angle was measured by the following formula. ${ }^{13}$

$$
\begin{aligned}
& \text { 圆 }=4^{*}[\operatorname{arc} \operatorname{Tan}(2 \mathrm{H} / \mathrm{L}) \\
& \mathrm{H}=\text { Height }(\mathrm{cms}), \mathrm{L}=\text { length }(\mathrm{cms})
\end{aligned}
$$

3. Pain at rest and on activity was assessed by a visual analogue scale $(\mathrm{VAS})^{11}$ which is a $10 \mathrm{~cm}$ line, drawn on a paper with 0 marking at one end and 10 at the other. Patient was explained that pain intensity increases from 0 to 10 . Patient was then asked to mark a point on the line determining his pain intensity at rest and on activity.

4. Low back pain and disability in post-partum phase was assessed by Roland - Morris low back pain and disability questionnaire (RMQ).12 It is a 24-point scale used to assess level of disability and to be sensitive to change over time in patient with low back pain.

Along with the above assessment criteria, patients were instructed to wear the abdominal binder from $7^{\text {th }}$ day postpartum up to 3 months post-partum. The abdominal binder is made of strong, elastic, air permeable and anti-sweating porous material. It has cotton lining to prevent allergy irritation. The area covered by the binder was from lower ribs to anterior superior iliac spine (ASIS). Contoured back panel to prevent shifting and rolling of the binder while movement. The side panels are elastic and soft providing stability and compression. Adjustable closure straps were present to tighten or loosen the belt. The subjects were asked to wear the abdominal binder throughout the day except when bathing, eating and sleeping. The binder was to be worn over the skin directly or on a thin layer of clothing. The side of the abdominal binder without the straps was pulled over by the subject's stomach with one hand. The side of the binder with straps was stretched across the subject's stomach and pulled to the centre of the abdomen. The straps were then fitted into the buckles. Thus, the binder could be easily adjusted according to the waist circumference of the patient. Patient was instructed not to wear the binder too tight or too loose as it may irritate the skin and produce difficulty in breathing creating discomfort.

Patients were asked to inspect their skin regularly for any signs of sensitivity. Along with the binder, patients were taught a core strengthening exercise regime which included transversus abdominal strengthening, tummy-tuck in exercise, head lift with posterior pelvic tilt 10 repetitions thrice a day from $7^{\text {th }}$ day post-partum to 3 months postpartum. The patients were screened monthly after $7^{\text {th }}$ day post-partum up to 3 months post-partum. The COVID-19 virus scenario, lockdown and travel restrictions in Maharashtra compelled us to take the follow up readings through video call medium.

\section{Statistical Analysis}

The analysis for this study was done with the help of repeated measures analysis of variance (ANOVA) test, GraphPad InStat 3.1 version to determine the effect of conventional abdominal binder on diastasis recti abdominis in post-partum women. The first reading was taken on $7^{\text {th }}$ day post-partum followed by monthly follow up readings up to 3 months post-partum. Repeated measures ANOVA test was used to determine reduction of DRA after using the conventional abdominal binder. Data represented as means and standard deviation, mean difference of all the outcome measures was calculated. It was statistically considered extremely significant with a $\mathrm{P}$ value of $<0.0001$.

\begin{tabular}{|c|c|c|c|c|}
\hline $\begin{array}{l}\text { Sl. } \\
\text { No. }\end{array}$ & Variables & Category & Frequency & Percentage \\
\hline \multirow{3}{*}{1} & \multirow{3}{*}{ Age (years) } & $20-25$ & 0 & 0 \\
\hline & & $25-30$ & 7 & 77.8 \\
\hline & & $30-35$ & 2 & 22.3 \\
\hline \multirow{2}{*}{2} & \multirow{2}{*}{ Number of offspring } & 1 & 5 & 55.5 \\
\hline & & 2 & 4 & 44.4 \\
\hline \multirow{2}{*}{3} & \multirow{2}{*}{ Primiparous } & Yes & 5 & 55.5 \\
\hline & & No & 4 & 44.4 \\
\hline \multirow{2}{*}{4} & \multirow{2}{*}{ Multiparous } & Yes & 4 & 44.4 \\
\hline & & No & 5 & 55.5 \\
\hline \multirow{4}{*}{5} & \multirow{4}{*}{ BMI $\left(\mathrm{kg} / \mathrm{m}^{2}\right)$} & Underweight & 0 & 0 \\
\hline & & Normal & 5 & 55.5 \\
\hline & & Overweight & 1 & 11.1 \\
\hline & & Obese & 3 & 33.3 \\
\hline \multirow{4}{*}{6} & \multirow{4}{*}{$\begin{array}{l}\text { Weight of the } \\
\text { baby(gms) }\end{array}$} & $<1000$ & 0 & 0 \\
\hline & & $<1500$ & 0 & 0 \\
\hline & & $<2500$ & 0 & 0 \\
\hline & & $>\quad 2500$ & 9 & 100 \\
\hline & Table 1. Percentas & $\begin{array}{l}\text { ind Frequency of } \\
\text { Related to DRA }\end{array}$ & rious $\mathrm{Pa}$ & rs \\
\hline
\end{tabular}

\section{RESULTS}

Based on the data accumulated and analyzed, the study was divided into 2 parts - As per the reading $7^{\text {th }}$ day post-partum before treatment and $3^{\text {rd }}$ month post-partum - after treatment. The findings were summarized in tabular and graphical formats. Table 2 describes all the statistical data of the outcome measures before treatment ( 0 month) and after treatment ( 3 month). The outcome measures assessed pre and post treatment were DRA - at, above and below umbilicus, lumbar lordosis, low back pain and disability in post-partum period. As per the statistical representation, the mean of diastasis recti abdominis that is the inter-recti distance above umbilicus before treatment on $7^{\text {th }}$ day postpartum is 51.87 and after treatment on $3^{\text {rd }}$ month postpartum is 37.76. The mean of diastasis recti abdominis that is the inter-recti distance at umbilicus before treatment on $7^{\text {th }}$ day post-partum is 59.39 and after treatment on $3^{\text {rd }}$ month post-partum is 41.19 . The mean of diastasis recti abdominis that is the inter-recti distance below umbilicus before treatment on $7^{\text {th }}$ day post-partum is 38.51 and after treatment on $3^{\text {rd }}$ month post-partum is 30.76 . The statistics represents that the mean of inter-recti distance or diastasis recti abdominis at all three levels - above umbilicus, at umbilicus and below umbilicus reduces as the treatment progresses. 


\begin{tabular}{|c|c|c|c|c|c|}
\hline Outcome Measures & $\begin{array}{c}\text { Before Treatment } \\
\text { (7 } \begin{array}{c}\text { th } \\
\text { Day Post-Partum) } \\
\text { Mean } \pm \text { SD }\end{array}\end{array}$ & $\begin{array}{l}\text { After Treatment } \\
\text { (3 Months) } \\
\text { Mean } \pm \text { SD }\end{array}$ & Mean Difference & P Value & F Value \\
\hline DRA above umbilicus & $51.87 \pm 12.37$ & $37.76 \pm 12.98$ & 14.11 & $<0.0001$ & 74.68 \\
\hline DRA at umbilicus & $59.39 \pm 14.24$ & $41.19 \pm 12.21$ & 18.20 & $<0.0001$ & 167.31 \\
\hline DRA below umbilicus & $38.51 \pm 12.13$ & $30.76 \pm 8.94$ & 7.75 & $<0.0001$ & 28.64 \\
\hline $\begin{array}{c}\text { Roland Morris low back pain and disability } \\
\text { questionnaire }\end{array}$ & $15.11 \pm 3.51$ & $1.77 \pm 0.83$ & 13.33 & $<0.0067$ & 93.60 \\
\hline Lumbar lordosis by flexible curve ruler & $57.22 \pm 10.06$ & $50.86 \pm 9.22$ & 6.36 & $<0.0001$ & 121.31 \\
\hline VAS on rest & $5.98 \pm 1.19$ & $1.74 \pm 0.48$ & 4.24 & $<0.0001$ & 98.90 \\
\hline VAS on activity & $7.48 \pm 1.86$ & $2.46 \pm 0.76$ & 5.03 & $<0.0001$ & 79.92 \\
\hline
\end{tabular}

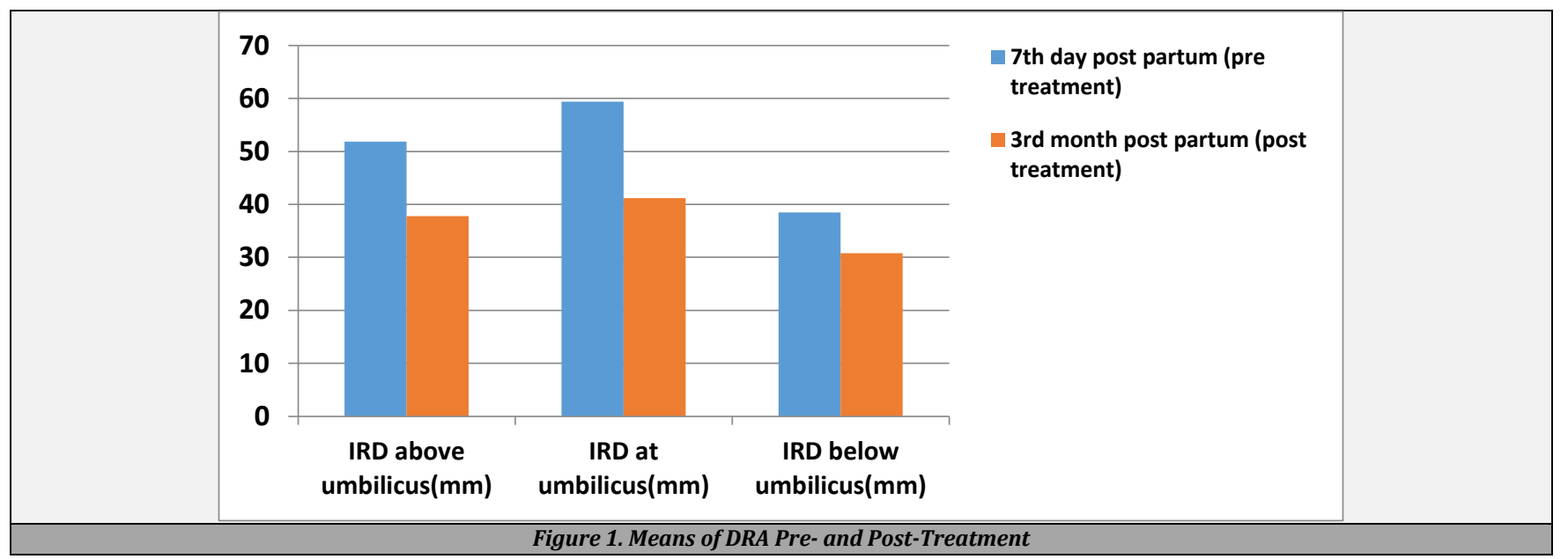

\section{DISCUSSION}

Hormonal changes during pregnancy, especially the effect of relaxin hormone and oestrogen with increasing size of the uterus to accommodate the fetus, stretches the anterior abdominal wall creating a gap between two bellies of rectus abdominis muscle. ${ }^{2} \mathrm{~A}$ core strengthening regime along with use of an abdominal binder is of utmost importance as binder mimics facial tension of thoraco lumbar fascia and supports the spine. Along with use of an abdominal binder, exercises are helpful to strengthen the core muscles in reduction of DRA. Exercises such as static abdominal contractions, pelvic rocking and leg sliding are given to decrease DRA. ${ }^{3}$

The study was conducted to determine the effect of conventional abdominal binder on diastasis recti abdominis in post-partum women. A dial up nylon caliper (inter-recti distance measurement), flexible curve ruler (lumbar lordosis measurement), Roland Morris low back pain and disability questionnaire (RMQ-low back pain and disability ) and visual analogue scale (VAS for pain at rest and on activity) was used for the study as they provide quantitative measures. The study was conducted in 4 parts: the first reading for the above parameters was taken on $7^{\text {th }}$ day post-partum and patients were taught the core strengthening exercise regime and were instructed to wear a conventional abdominal binder from $7^{\text {th }}$ day post-partum to 3 months post-partum. After the first reading on $7^{\text {th }}$ day post-partum, monthly follow-up readings were taken up to 3 months post-partum. Due to the Covid-19 pandemic, the statewide lockdown and travel restrictions, the follow up readings up to $3^{\text {rd }}$ month postpartum were taken via video conferencing.

The results of first part of the study shows that, as the treatment progresses mean values of DRA, lumbar lordosis, RMQ scores and VAS at rest and on activity decreases linearly per month. The mean of DRA above umbilicus on $7^{\text {th }}$ day post- partum - before treatment is 51.87 which decreases to 37.76 after 3 months of treatment, the $\mathrm{P}$ value is $<0.0001$ and $\mathrm{F}$ value is 74.68 which is considered to be extremely significant. DRA at umbilicus on $7^{\text {th }}$ day post-partum before treatment is 59.39 and DRA after 3 months of treatment is 41.11 with $P$ value $<0.0001$ and $F$ value 167.31 which is again considered to be extremely significant. Mean value of DRA below umbilicus on $7^{\text {th }}$ day post-partum is 38.51 which reduces to 30.76 after a 3 months of treatment protocol with $\mathrm{P}$ value < 0.0001 and $F$ value 28.64 which is extremely significant. The mean values of Roland Morris low back pain and disability questionnaire, lumbar lordosis measurement and VAS at rest and on activity on $7^{\text {th }}$ day post-partum - before treatment are $15.11,57.22,5.98$ and 7.48 respectively which decreases to $1.77,46.86,1.74$ and 2.46 respectively. The $P$ value of scores of RMQ is $<0.0067$ and $F$ value is 93.60 which are considered to be extremely significant. The $\mathrm{P}$ value of lumbar lordosis, VAS at rest and on activity is $<0.0001$ and $F$ values are $121.31,98.90$ and 79.92 respectively.

It was observed during this study that the only use of abdominal binder reduces the abdominal girth and provides support in post-partum period but the combined treatment of an abdominal binder and a core strengthening exercises not only reduces the girth but also helps to strengthen the core muscles to reduce DRA.

The lacuna of this study is that the conventionally used abdominal binder is not according to the anatomical structure of the body which provides less intensive force in reduction of DRA.

\section{CONCLUSIONS}

The mean value of DRA at all three levels decreases with the help of abdominal binder and core strengthening exercise 
regime. Hence, the abdominal binder and core strengthening exercises were effective in reducing the inter-recti distance DRA.

Data sharing statement provided by the authors is available with the full text of this article at jemds.com.

Financial or other competing interests: All Authors received grants from Krishna Institute of Medical Sciences "Deemed to be University". Disclosure forms provided by the authors are available with the full text of this article at jemds.com.

We are extremely thankful and grateful for the help provided by Dr. Kashinath Sahoo, HOD - Department of Orthotics and Prosthetics, KIMSDU, Karad.

\section{REFERENCES}

[1] Kahle W, Leonahardt H, Platzer W. Anatomie. Appareil Locomoteur. Paris, France: Flammarion Medicine Science 1991.

[2] Boissonnault JS, Blaschak MJ. Incidence of diastasis recti abdominis during the childbearing year. Phys Ther 1988;68(7):1082-86.

[3] Bursch SG. Inter rater reliability of diastasis recti abdominis measurement. Phys Ther 1987;67(7):1077-9.

[4] Boissonnault JS, Kotarinos RK. Diastasis recti in obstetric and gynecologic physical therapy In: Wilder E, ed. Clinics in Physical Therapy: Obstetrics and Gynecological Physical Therapy. New York, NY: Churchill Livingstone 1988:63-81.

[5] Rath AM, Attali P, Dumas JL, et al. The abdominal linea Alba: an anatomo-radiologic and biomechanical study. Surg Radiol Anat 1996;18(4):281-8.
[6] Boxer S, Jones S. Intra-rater reliability of rectus abdominis diastasis measurement using dial calipers. Aust Physiother 1997;43(2):109-14.

[7] Keeler J, Albrecht M, Eberhardt L, et al. Diastasis recti abdominis. J Women's Health Phys Ther 2012;36(3):131-42.

[8] Sheppard S. The role of transversus abdominus in postpartum correction of gross divarication recti. Man Ther 1996;1(4):214-6.

[9] El-Mekawy HS, Eldeeb AM, El-Lythy MA, et al. Effect of abdominal exercises versus abdominal supporting belt on post-partum women abdominal efficacy and rectus separation. World Academy of Science, Engineering and Technology. International Journal of Medical, Health, Biomedical, Bioengineering and Pharmaceutical Engineering 2013;7(1):742.

[10] Khandale SR, Hande D. Effects of abdominal exercises of diastasis recti in postnatal women. Int J Health Sci Res 2016;6(6):182-91.

[11] De Boer AGEM, Van Lanshot JJB, Stameier PFM, et al. Is a single-item visual analogue scale as a valid reliable and responsive as multi-item scales in measuring quality of life? Qual Life Res 2004;13(2):311-20.

[12] Caporaso F, Pulkovski N, Sprott H, et al. How well do observed functional limitations explain the variance in Roland Morris scores in patients with chronic nonspecific low back pain undergoing physiotherapy? Eur Spine J 2012;21(Suppl 2):S187-95.

[13] Taylor S. Validity and reliability of flexi curve to measure cervical lordosis. ProQuest 2015 